\title{
PRINCIPIO PRECAUTORIO Y RIESGOS AMBIENTALES A PROPÓSITO DE LA GENERACIÓN DE RADIACIONES NO IONIZANTES: EL CASO DE LAS ANTENAS DE TELEFONÍA CELULAR EN LA JURISPRUDENCIA ARGENTINA
}

María Valeria Berros*

\section{Resumen}

El presente trabajo se construye a partir de un estudio de caso, efectuando un recorrido respecto de la jurisprudencia argentina en materia de campos electromagnéticos. A partir del análisis del supuesto seleccionado, observamos las dificultades que la racionalidad precautoria genera en el funcionamiento del derecho de daños, ante la gestión de hipótesis de hecho inmersas en un contexto de controversia científica.

Palabras-clave: Principio Precautorio. Riesgos Ambientales. Radiaciones no Ionizantes. Antenas de telefonia.

\section{Introducción}

En el presente trabajo intentamos aproximarnos a la forma mediante la cual, en la jurisprudencia argentina, se aplica el principio de precaución a propósito del caso de la instalación de antenas de telefonía celular, como ejemplo de hipótesis de hecho cuyas consecuencias dañosas son controvertidas.

Este recorrido permite introducirnos en la problemática que la incerteza genera para el funcionamiento del derecho de daños. Cabe aclarar, en principio, que cuando nos referimos al derecho de daños en Argentina, no lo hacemos como sinónimo de derecho de la responsabilidad civil, debido a que ambas denominaciones corresponden a concepciones diferentes. El derecho de daños asume funciones que exceden al clásico derecho de la responsabilidad civil - concebido como herramienta de reparación del daño causado y sanción de la conducta antijurídica y culpable -, abarcando otras nuevas, como la preventiva y la precautoria. Las racionalidades constitutivas de estas funciones son diversas, y se da lugar a la necesidad de pensar de qué modo se relaciona el núcleo duro del sistema de responsabilidad civil con diversos subsistemas, tales como el daño a los consumidores o el daño ambiental, cuyas racionalidades constitutivas difieren, e incluso se contraponen al sistema positivizado en el Código Civil.

\footnotetext{
*Abogada, Miembro del Grupo de Investigación sobre Bioregulaciones (FCJS, UNL, Argentina), Practicante docente en las asignaturas "Derecho de Daños" e "Introducción a la Sociología" en la Facultad de Ciencias Jurídicas y Sociales de la Universidad Nacional del Litoral (Argentina).
} 
A los efectos de desarrollar este estudio, hemos de considerar el caso de la instalación de antenas como un supuesto "híbrido"', caracterizado por constituirse como embrollo de "[...] elementos de la ciencia, de la política, de economía, de derecho, de religión, de técnica, de ficción [...]". Los híbridos, "invisibles" bajo los parámetros de la "constitución moderna”, se encuentran en proceso de proliferación a partir de los últimos años, lo cual se denota, en mayor medida, en aquellas cuestiones relacionadas con el medio ambiente y la salud humana. Éstos se caracterizan por la imposibilidad de un abordaje unilateral, debido a que, ni las ciencias de la naturaleza ni las ciencias de la cultura, logran dar cuenta del fenómeno por sí mismas, es decir no tienen herramientas suficientes para explicarlo ${ }^{3}$.

En segundo lugar, añadimos a la noción de híbrido la idea de incerteza. Esta es una de las características del supuesto de los campos electromagnéticos emanados de las antenas de telefonía celular, debido a que no se conocen acabadamente sus posibles consecuencias nocivas.

A los fines de estudiar el problema, proponemos la realización de un análisis de los discursos que se presentan en la gestión del mismo, dentro de los cuales nuestro objeto de estudio está focalizado en el plano de las regulaciones jurídicas y el tratamiento jurisprudencial que se le asigna.

Dentro del ámbito legislativo, relevamos todas aquellas normas que rigen el tema de las radiaciones no ionizantes, ya sea de manera directa ${ }^{4}$ (por ejemplo, aquellas resoluciones que fijan límites

\footnotetext{
${ }^{1}$ A partir de esta perspectiva, se propone una conjugación de los elementos provenientes de los enfoques que la teoría social ha elaborado en relación al riesgo. Uno de ellos, considerado "realista", que asume la idea de riesgo como algo existente ontológicamente, lo cual proviene del marco de las tecnologías actuariales, ingeniería, psicología. Asimismo, se consideran como teorías que presentan un "realismo débil" a las tesis de Ulrich Beck y de Anthony Giddens. El segundo de ellos, llamado "constructivista", concibe al riesgo como fenómeno socio cultural. En este marco se destacan diversos puntos de vista como el de Mary Douglas, los "governmentality studies", y la tesis que considera al riesgo como concepto.

2 “"...] la modernidad es entonces una ilusión? No es mucho más que una ilusión y mucho menos que una esencia [...]".LATOUR, Bruno. Nous n'avons jamais été modernes: essai d'anthropologie symétrique: la decouverte. Paris: [s.n.], 1997. p. 60.

${ }^{3}$ La separación tajante que la "constitución moderna" postula entre lo natural y lo cultural, es decir entre lo "no humano", lo fáctico; y, por otro lado, lo "humano", lo moral, no es adecuada para otorgar tratamiento a este tipo de problemáticas. Las mismas exceden el marco de los dos polos construidos en base a esta constitución moderna: aquel encargado del plano no humano, fáctico, y aquel otro a cargo de lo humano, lo moral. Los híbridos no pueden ser tratados adecuadamente a partir de uno de los dos polos individualmente dado que suponen de herramientas y conceptos provenientes de ambas esferas. LATOUR, Bruno. Nous n'avons jamais été modernes: essai d'anthropologie symétrique: la decouverte. Paris: [s.n.], 1997

${ }^{4}$ Resolución N ${ }^{\circ}$ 202/ 1995 del Ministerio de Salud de la Nación, Resolución N 3690/2004 de la Comisión Nacional de Comunicaciones, Ley sobre Telefonía Celular de la Provincia de Santa Fe $N^{\circ} 12.362 / 2004$, Resolución N ${ }^{\circ}$ 900/2005 de la Dirección de Política Ambiental de la Provincia de Buenos Aires, Ordenanza N ${ }^{\circ} 392 / 2002$ de la Municipalidad de José C. Paz.
} 
de emisión) como de manera indirecta ${ }^{5}$ (verbigracia, la Ley General de Política Ambiental Nacional). Dentro del marco jurisprudencial, consideramos las sentencias recaídas sobre este caso en Argentina ${ }^{6}$.

Sin perjuicio del recorte efectuado, y considerando esta salvedad, mediante los discursos analizados se indaga sobre la articulación y ensamblaje de prácticas científicas, políticas y sociales, que provienen del sector experto, del político y de la sociedad civil, respectivamente.

Por otra parte, contextualizamos el discurso normativo y jurisprudencial, teniendo en cuenta dos regímenes de prácticas, que nos permiten explorar su influencia focal en la construcción de los primeros. Una de ellas, la de los medios de comunicación, a partir de la localización de artículos periodísticos que han versado sobre la temática. La segunda, el sistema científico tecnológico, mediante la incorporación de algunos informes de expertos.

A efectos de sustentar teóricamente el análisis, partimos de los diferentes paradigmas de tratamiento social del riesgo que plantea François Ewald, entendiendo como tales aquel conjunto de prácticas, discursos, combinaciones, respecto de los cuales es dable la identificación de una cierta lógica o racionalidad.

El mencionado autor establece la existencia de tres paradigmas: responsabilidad, solidaridad y seguridad. El primero de ellos parte de la idea de culpa como factor atributivo de la responsabilidad, concibiendo a ésta como un regulador de las conductas humanas. El segundo, introduce la idea de riesgo y el desarrollo y expansión de la técnica del seguro como mecanismo de repartición de riesgos. Por último, el paradigma de seguridad, da cuenta de casos inmersos en un contexto de incerteza científica, destacándose la posibilidad eventual de daños graves o irreversibles; lo cual conduce a la introducción del principio precautorio, como racionalidad constitutiva del mismo. ${ }^{7}$

${ }^{5}$ Leyes nacionales: Ley de Política Ambiental N ${ }^{\circ}$ 25675/ 2002, Ley de Régimen de Libre Acceso a la Información Ambiental $\mathrm{N}^{\circ}$ 25831/ 2000. Leyes y decretos provinciales: Ley de Medio Ambiente y Desarrollo Sustentable $N^{\circ} 11717 / 1999$ de la Provincia de Santa Fe, Decreto reglamentario $N^{\circ} 101 / 2003$ (Reglamenta la Ley $N^{\circ} 11717 / 1999$ de la Provincia de Santa Fe), Decreto reglamentario ${ }^{\circ}$ 101/2003 (reglamenta la Ley 11717/1999).

6 Sentencia de Primera Instancia y de la Cámara Civil y Comercial de Santa Fe, Sala $2^{\circ}$. 04.05.2001. "Farina, Pablo M. c/ Compañía de Radiocomunicaciones Móviles S.A. s/ Acción de amparo"; Sentencia del Tribunal Superior de Córdoba, 11.03.2003. "Castellani, Carlos y E. y otros"; Sentencia respecto de medida cautelar en Primera Instancia del Juzgado en lo Contencioso, Administrativo y Tributario Número 12 de la Ciudad Autónoma de Buenos Aires, 18.10.2006. "Peino, Leonardo Esteban y otros contra GCBA sobre amparo (art.14 CCABA)", Sentencia del Juzgado en lo Civil N ${ }^{\circ} 105$ de Buenos Aires, 09.02.07 "Espíndola, M. c/ Movicom Bellsouth s/ Daños y Perjuicios" Causa 17008/03; Sentencia de la Cámara Federal de Apelaciones de La Plata - Sala I, 28.06.07 "Telefónica Comunicaciones Personas S.A. c/ Municipalidad de Lanús s/ acción declarativa de inconstitucionalidad"; Sentencia del Juzgado en lo Contencioso, Administrativo y Tributario Número 12 de la Ciudad Autónoma de Buenos Aires, 18.09.07. "Uyemas, Héctor Ubaldo c/ Gobierno de la Ciudad de Buenos Aires s/ amparo (art. 14 CCABA).

7 EWALD, François. Le retour du malin génie. Esquisse d'une philosophie de la précaution. In: GODARD, Olivier (Dir.). Le principe de précaution dans la conduite des affaires humains" Paris:Editorial de la Maison des Sciences de l'homme, 1997. 
Nuestra tesis sostiene que, aunque el caso bajo análisis puede encuadrarse dentro del marco este último paradigma, a partir de los discursos de los actores sociales intervinientes emerge un panorama en el que se conjugan elementos de los tres paradigmas de tratamiento social del riesgo.

Esta hipótesis, se complejiza y amplía al considerar la promulgación en el año 2002 de la Ley de Política Ambiental N ${ }^{\circ} 25.675$, dado que la misma positiviza, como principio de política ambiental, el precautorio. Lo expuesto genera que, cuando el caso se concibe como atentatorio al medio ambiente, se facilite la aplicación de la lógica precautoria. Por contraposición, cuando se lo considera como lesivo de la salud humana se torna más dificultosa su aplicabilidad.

\section{La instalación de antenas de telefonía celular: ¿Posibles consecuencias perjudiciales?}

\subsection{La propagación de la telefonía móvil}

La generación de campos electromagnéticos no es un fenómeno que sólo se relacione con la instalación de antenas de telefonía celular, sino que existen una multiplicidad de agentes generadores de este tipo de radiaciones como las líneas de alta tensión, computadoras, electrodomésticos, radares, entre muchos otros.

En el caso que nos ocupa en el presente estudio, podemos sí afirmar que existió un avance muy importante en la expansión del uso de telefonía celular en los últimos años, lo cual trajo como corolario un correlativo aumento de las instalaciones de antenas que permitan su funcionamiento ${ }^{8}$.

\footnotetext{
8 Por ejemplo, en la ciudad Autónoma de Buenos Aires (Argentina) se han instalado ya 600 antenas en 48 de los 45 barrios que la componen. Asimismo, el número de aparatos celulares en el país creció en los últimos años de 19,3 a 28,3 millones, de lo cual deviene como consecuencia la instalación de aproximadamente - diez antenas por día; según informe aparecido en el diario argentino "La Nación" de fecha 5 de noviembre de 2006. Por otra parte, el 15 de febrero de 2007, concluyó en Barcelona el "3GSM World Congreso", del cual una de las empresas de telefonía (Nokia) extrae como conclusión que el sector de la telefonía móvil es uno de los más importantes actualmente. Estima que a fin del año en curso habilitará tres millones de líneas telefónicas, número que asciende a cuatro millones para el año 2010 (Journal "20 Minutes" de fecha 16 de febrero de 2007, Paris). En consonancia con estas ideas, se sostiene en "La Nación Revista" de fecha 27 de agosto de 2007 que "[...] La telefonía móvil es una de las industrias más dinámicas del mundo. Entre 2001 y 2006 sumó 1600 millones de usuarios a nivel global [...] Según el Indec, en junio de 2007 había en Argentina unos 36,6 millones de celulares en servicio. Esto equivale a una penetración del $92,2 \%$ de la población total del país. La cámara de empresas de comunicaciones (Cicomra) indica que en ese mes se realizaron unos 2105 millones de llamadas. En 2003, las líneas de telefonía móvil superaron a las de telefonía fija en nuestro país. De 2002 a 2006, el mercado creció el $262 \%$ en número de líneas, y pasó de 7 millones a 24 millones de líneas activas, según la Consultora Prince \& Cooke. En cuanto a la facturación del sector, en el mismo período subió de 1950 millones a 7580 millones de pesos, más del $289 \%$, superando al mercado de telefonía fija [...]”.
} 
En virtud de lo expuesto, y dado que se trata de un fenómeno cuya producción también subyace a la naturaleza, podría pensarse que no tendría efectos negativos respecto de la salud humana o el medio ambiente. Pero, por el contrario, el eje en base al cual se centra la controversia que seleccionamos refiere a la posible dañosidad que reviste la generación de ondas electromagnéticas no ionizantes. El fundamento es que la existencia de este tipo de radiaciones ya no se encuentra dentro de sus parámetros naturales, sino que su índice ha sido incrementado notoriamente en virtud de las actividades anteriormente referidas.

El debate se centra en los efectos que podría tener para la salud del hombre la exposición continua a diversos agentes emisores, aún en los casos en que las ondas generadas por cada agente individualmente considerado, se halle por debajo de los límites legales autorizados, lo cual nos conduce a la idea postulada por Ulrich Beck respecto del solapamiento de los efectos secundarios no calculados en relación a los riesgos. ${ }^{9}$

\subsection{Estado de la controversia científica: entre la constelación de investigaciones y la organización de grupos de expertos}

En materia de campos electromagnéticos podemos identificar la coexistencia de, por un lado, numerosa información científica vertida en diversas publicaciones en las que se identifican posiciones encontradas; $y$, de otra parte, la organización de grupos de expertos a los fines de estudiar la problemática.

Dentro del último caso, destacamos las conclusiones ${ }^{10}$ que presenta la Organización Mundial de la Salud. Éstas, han sido objeto de una publicación en el año 2005, denominada "Estableciendo un diálogo sobre los campos electromagnéticos", en la que se estableció que los campos electromagnéticos de baja frecuencia son "[...] posibles cancerígenos en seres humanos basados en estudios epidemiológicos de leucemia en niños [...]”. En relación a los campos de alta frecuencia, sostiene que "[...] el balance de la evidencia a la fecha sugiere que la exposición a campos de RF de bajo nivel (tales como los emitidos por teléfonos móviles y sus estaciones bases), no causan efectos adversos en la salud [...]" (ORGANIZACIÓN MUNDIAL DE LA SALUD, 2005, p. 7).

Cabe destacar, que estas aseveraciones no son compartidas por otros grupos dentro de las ciencias, de allí que sostenemos que estamos ante una situación de controversia científica, ya que no se pueden establecer conclusiones en relación a los efectos de las radiaciones no

9 BECK, Ulrich. La sociedad del riesgo: hacia una nueva modernidad. [Barcelona]: Paidos, 1998.

${ }^{10}$ Las mencionadas conclusiones tienen carácter provisorio hasta tanto la OMS vuelva a expedirse al término de su estudio respecto de las consecuencias devenidas de la generación de ondas electromagnéticas. 
ionizantes. Como un ejemplo de ello, podemos referirnos a la Resolución de Benevento ${ }^{11}$, en la cual se destaca que

\begin{abstract}
Nuevas evidencias acumuladas indican que hay efectos adversos para la salud como resultado de la exposiciones laboral y pública a los campos eléctricos, magnéticos y electromagnéticos, o CEM, en los niveles de exposición actuales...Los estudios epidemiológicos así como los experimentos in vivo e in vitro demuestran que la exposición a ciertos campos electromagnéticos de baja frecuencia puede aumentar el riesgo del cáncer en niños e inducir otros problemas de salud en niños y adultos. Además, hay una evidencia epidemiológica acumulada que indica un riesgo creciente de tumor cerebral por el uso a largo plazo de teléfonos móviles $[\ldots]$.
\end{abstract}

\title{
2.3 Acerca de la fijación de límites máximos de exposición y normas de seguridad
}

Dentro del discurso normativo, se visualiza que el eje central de las regulaciones con respecto a la temática está dado por la implementación de normas de seguridad y valores límite de generación.

Mediante el uso de esta “estrategia de standarización”, podemos vislumbrar cómo la utilización de esta tecnología jurídica de establecimiento de topes máximos, sustentada en ciertas pautas establecidas científicamente, permite una suerte de "normalización del riesgo". Normalización, que viene dada a partir de una alianza que puede pensarse como "estratégica" entre el derecho y la ciencia, mediante la cual el primero ratifica los discursos del expertise científico. De allí

[...] la importancia de las metanormas de las definiciones de riesgo y, por tanto, de las normas legales que describen la atribución de causas y consecuencias a los actores en circunstancias de elevada complejidad y contingência $[\ldots] .^{12}$

En consonancia con esta lógica, en el caso argentino, se aprobó por Resolución del Ministerio de Salud No 202/1995, el "Estándart Nacional de Seguridad para la exposición a radiofrecuencias comprendidas entre $100 \mathrm{KHz}$ y $300 \mathrm{GHz}$ ", donde se establecen los límites máximos de irradiación que devienen de cumplimiento obligatorio según la Resolución $\mathrm{N}$ - 530/2000 de la Secretaría de Estado de Comunicaciones. Por su parte, la Resolución N - 3690/2004 de la Comisión Nacional de Telecomunicaciones, establece que los sistemas irradiantes se deben adaptar a las condiciones dispuestas por la Resolución $N^{\circ}$ 530/2000.

11 COMISIÓN INTERNACIONAL PARA LA SEGURIDAD ELECTROMAGNÉ-TICA (ICEMS). Resolución de Benevento. Montepulciano, 19 sep. 2006. Disponible em: <www.icems.eu>. Fecha de acceso: 10 dic. 2006.

${ }^{12}$ BECK, Ulrich. La sociedad del riesgo global. Madrid: Siglo XXI de España, 2002. p. 86. 
El control de cumplimiento de los límites de generación de radiaciones no ionizantes, está a cargo de la Comisión Nacional de Comunicaciones.

Ahora bien, la potestad a los efectos de autorizar y ubicar territorialmente la instalación de agentes generadores, se encuentra a cargo del gobierno local, quien es el que determina los requisitos necesarios para lograr la habilitación.

Dentro de este marco, se otorga trascendencia al procedimiento técnico - jurídico de evaluación de impacto ambiental, como requisito que debe presentarse previamente ${ }^{13}$ a la instalación.

En la caso de la provincia de Santa $\mathrm{Fe}$, en Argentina, existe una ley específica en la materia, $\mathrm{N}^{\circ} 12.362$ promulgada en el año 2004, que en su artículo 1 determina su ámbito de aplicación:

[...] la presente ley establece las normas a las que deberán ajustarse los elementos técnicos necesarios para transmisión de comunicaciones y las instalaciones complementarias de telefonía móvil con sus diferentes tipos de soportes y estructuras, como así también los sistemas de enlace troncal (trunking), sin perjuicio de las mayores exigencias que en el ámbito de sus jurisdicciones podrán fijar los Municipios y Comunas, pudiendo definir incluso la prohibición de su instalación en todo el distrito o en determinadas áreas del mismo $[\ldots]$.

Por su parte, en la misma ley provincial, se establecen algunas prohibiciones en cuanto a la ubicación de las antenas de telefonía móvil, dejando a cargo de la autoridad municipal o comunal la determinación exacta en cuanto a los límites de la interdicción. De este modo, se afirma en el artículo 8, que

[...] Se prohíbe en todo el territorio de la provincia de Santa Fe, la instalación de todo tipo de columna, soporte, torres o similares para la telefonía móvil y sistemas de trunking, en terrenos o edificios particulares o públicos, sin previo otorgamiento del permiso de habilitación correspondiente, de acuerdo a la ley, su reglamentación, y las ordenanzas locales aplicables [...].

A lo cual se agrega, en el artículo 9:

[...] Queda prohibida la instalación de estructuras soporte de antena cualquiera sea su tipología en plazas o parques y en inmuebles ubicados frente a éstos, y/o en los distritos especificados en los Códigos Urbanos; que cada Municipio o Comuna determine por legislación y/o decreto reglamentario, en función de la presente norma $[\ldots]$.

\footnotetext{
${ }^{13}$ El carácter previo no sólo se deduce de la naturaleza misma del instituto, sino que a la vez está positivizado en diferentes normativas: art. 2 de la Ley de Telefonía Celular de la Provincia de Santa Fe, art. 11 de la Ley General del Ambiente, art. 18 de la Ley de Medio Ambiente y Desarrollo Sustentable de la Provincia de Santa Fe.
} 
Por último, determina una prohibición en función de la identificación de ciertos "sitios sensibles"14.

[...] A partir de la presente ley queda prohibida la instalación de todo tipo de antenas para telefonía móvil con sus diferentes tipos de soportes y estructuras, como así también los sistemas de trunking; en inmuebles donde funcionen establecimientos educacionales, clubes, instituciones intermedias, centros de salud y cualquier otro ámbito de concurrencia masiva de público y en los terrenos lindantes a los mismos [...].

La potestad local a efectos de autorizar la instalación de antenas de telefonía local, fue objeto de decisorio judicial por parte de la Cámara Federal de Apelaciones de la Plata, Sala I, en fecha 28.06.07 en autos caratulados: "Telefónica Comunicaciones Personas S.A. c/ Municipalidad de Lanús s/ acción declarativa de inconstitucionalidad”.

En este caso, la empresa de telefonía celular interpone una acción declarativa de inconstitucionalidad contra la Municipalidad de Lanús a los fines de que ésta se abstenga de aplicar a Telefónica Comunicaciones Personales S.A. las disposiciones del Decreto 1750/04 y que proceda al inmediato levantamiento de la clausura y desactivación que ya se hubieren efectivizado sobre las antenas localizadas en jurisdicción de esa localidad.

Esta acción es acogida por el a quo, por lo que la demandada apela la sentencia. En la segunda instancia, por el contrario, la Cámara resuelve

[...] Revocar la resolución apelada, y disponer que la empresa accionante deberá acompañar en autos un estudio científico detallado sobre la potencial nocividad en la salud pública de los campos electromagnéticos generados por las estaciones de base y tecnologías inalámbricas, sin perjuicio de la obligación de adecuar las estaciones existentes a las pautas reglamentarias dispuestas en las Ordenanzas $\mathrm{N}^{\mathrm{o}}$ 9187/00 y 9438/01 de la Municipalidad de Lanús [...].

Los fundamentos en los cuales se sustenta la decisión establecen pautas claras en cuanto a las potestades de las autoridades locales respecto de la protección del ambiente. Es así como se afirma

[...] El derecho a un ambiente sano exige el ejercicio del deber de preservación que compete a las autoridades, cuando el interés es difuso y afecta a toda la comunidad, ese interés es público, es titular es la comunidad y el legitimado el Estado. Concordantemente con este criterio, la Ley General del Ambiente No 25.675 legitima al Estado

\footnotetext{
${ }^{14}$ Parafraseamos aquí el concepto asignado a este tipo de lugares en el informe: "Les téléphones mobiles. Leurs stations de base et la santé. État de connaissances et Recommandations". Rapport au Directeur Général de la Santé. 16 janvier 2001, Paris, Francia. Este fue en primer informe confeccionado a los efectos de estudiar las consecuencias sanitarias de las instalaciones de telefonía móvil en Francia. En ese mismo año, se crea - por ley del 9 de mayo - la Agencia Francesa para la Seguridad Sanitaria y Medioambiental (AFSSE); que dio tratamiento al tema de la exposición a campos electromagnéticos en dos oportunidades, mediante la presentación de sendos informes en los años 2003 y 2005.
} 
nacional, provincial y municipal para obtener la recomposición del ambiente danado [...],

[...] Los municipios se encuentran legitimados activamente en cuestiones de incidencia colectiva, en su carácter de "afectado" y en representación de los habitantes pues ejerce su poder de policía no sólo a través del dictado de decretos y ordenanzas sino también mediante la adopción de aquellas medidas preventivas tendientes a evitar su incumplimiento $[\ldots]$.

Asimismo, destacamos la introducción de la lógica precautoria como sustento para adoptar el decisorio, dada la potencial nocividad de la instalación de antenas. Expresamente se cita el texto de la normativa legal que positiviza el principio, Ley $25.675 / 02$.

Por otra parte, se advierte que

[...] Es indudable que frente a las modernas tendencias de nivel internacional a favor de los derechos fundamentales del hombre, como son el derecho a la salud y a un ambiente sano, que han superado notoriamente los agotados principios del derecho decimonónico e iusprivatista del siglo pasado, es imperativo transformar las concepciones judiciales para brindar tutela a los fenómenos reales de la vida colectiva, típicos de la sociedad moderna, que ponen en escena intereses impersonales y difusos, incuestionablemente dignos de la más enérgica y anticipada protección y, en ese marco, el derecho a vivir en un medio ambiente agradable, viene entendiéndose como una ampliación de la esfera de la personalidad humana: un atributo fundamental de los indivíduos [...],

lo cual permite vislumbrar que en este caso se visualizan las incompatibilidades y dificultades de funcionamiento del sistema codificado, a efectos de gestionar cuestiones relativas al medio ambiente.

\subsection{Sobre los afectados, acerca de la conformación de grupos}

Se observa que ciertos afectados, identificados en los casos jurisprudenciales en Argentina, se presentan agrupados. Su vinculación está dada por la ubicación espacial respecto de la fuente generadora de campos electromagnéticos. En general éstos sostienen que la incertidumbre sobre la dañosidad de la exposición a campos electromagnéticos es, por sí misma, suficiente para tomar medidas al respecto, más aún cuando se encuentra en juego la salud humana.

La preocupación por parte de vecinos por la instalación de antenas, se refleja, por ejemplo, en el caso “Castellani, Carlos y E. y otros", en el cual se busca la suspensión y eventualmente la erradicación de cuatro antenas de telefonía celular en el radio urbano de la localidad de Oncativo (Provincia de Córdoba), considerando que las mismas violan los derechos constitucionales de propiedad, a la salud y a un ambiente sano. 
Por otra parte, en el supuesto "Peino, Leonardo Esteban y otros contra GCBA sobre amparo (art.14 CCABA)", interviene también un grupo, específicamente, un conjunto de padres, preocupados por la salud de sus hijos debido al funcionamiento de una antena de telefonía móvil instalada en el techo de la misma ${ }^{15}$.

\section{Un panorama controvertido, complejidad para el derecho}

Efectuada esta primera aproximación a la problemática podemos introducirnos en el inconveniente que se presenta para el derecho debido a que el mismo debe lidiar con una situación en la cual prima la controversia. El mismo se relaciona, fundamentalmente, con dos de los presupuestos de la responsabilidad, que son el daño y la vinculación causal.

En el caso bajo análisis, no se puede determinar fehacientemente el vínculo entre la generación de radiaciones no ionizantes y el daño en la salud que podría provenir de la exposición continua a campos electromagnéticos, aún por debajo de los niveles máximos de emisión.

Lo expuesto, dificulta la identificación de las condiciones de resarcibilidad del daño erigidas tradicionalmente. Dentro del esquema originario de la responsabilidad, por el contrario, se presentan ciertos parámetros constitutivos cuyo basamento se corresponde a otro tipo de hipótesis en las cuales existe la posibilidad de identificar el perjuicio y, asimismo, determinar su agente productor.

Esa estructuración se torna rígida a los efectos de gestionar esta hipótesis de hecho compleja, que se encuentra dentro de los casos a los que se asigna carácter híbrido. ${ }^{16}$

Es por ello que se sostiene que estamos ante la emergencia de un nuevo paradigma de tratamiento social del riesgo, a cuya conformación asistimos desde fines del siglo XX y cuyo

\footnotetext{
${ }^{15}$ Este tipo de preocupación, fue objeto en Francia, de la conformación de algunas asociaciones - que plantearon como estrategia la aplicabilidad del principio de precaución a la instalación y expansión de las antenas de telefonía móvil -, por ejemplo, en el marco del affaire de Saint - Syr - L' Ecole. Resuelto por el Conseil d'Etat francés en fecha 18 de febrero de $2005\left(\mathrm{~N}^{\circ}\right.$ 272874). El Conseil d'Etat decide rechazar la demanda de la Mairie de Saint - Cyr - L'Ecole que solicita la anulación del decreto de fecha 3 de mayo de 2002 fundándose en la comisión de un error manifiesto por parte del Primer Ministro en la apreciación de los riesgos a los cuales el público se encuentra expuesto. Analiza la legalidad externa e interna del decreto atacado. Respecto de su legalidad externa sostiene que " [...] le gouvernement s'est borné, ainsi qu'il y était habilité par ces dispositions, qui ont valeur législative, à fixer les valeurs limites d'exposition du public aux champs électromagnétiques émis par les équipements utilisés dans les réseaux de télécommunications [...]". En relación a su legalidad interna afirma que "[...] les limités d'exposition imposées par le décret attaqué, qui correspondent à celles préconisées par la recommandation de l'Union Européenne, tiennent compte des marges de sécurité destinées à protéger le public contre tout effet y compris à long terme, de l'exposition aux ondes électromagnétiques ou pris des mesures que ne seraient pas proportionnées aux précautions qui s'imposent dans cette matière [...]"

${ }^{16}$ LATOUR, Bruno. Nous n'avons jamais été modernes: essai d'anthropologie symétrique: la decouverte. Paris: [s.n.], 1997.
} 
pilar constitutivo es la racionalidad precautoria. ${ }^{17}$ Esta lógica es diferente e, incluso, deviene contradictoria respecto de las que subyacen al clásico derecho de la responsabilidad civil, lo que da lugar a un conflicto en el marco de sus pilares epistemológicos.

Es nuestra tesis que, si bien el caso de la instalación de antenas de telefonía celular puede encuadrarse dentro del marco de una "situación de precaución", a partir de los discursos de los actores sociales intervinientes emerge un panorama en el que se conjugan elementos de los tres paradigmas de tratamiento social del riesgo que presenta F. Ewald.

Las diferentes racionalidades que podemos identificar se conforman por un conjunto de prácticas, combinaciones, que exceden el marco de la normativa jurídica y su aplicación jurisdiccional. Sin perjuicio de ello, - y considerando esta salvedad - pensamos que mediante el análisis de los discursos que allí se patentizan, se puede visualizar la emergencia de disímiles racionalidades en el tratamiento que se otorga al caso seleccionado; lo que genera un panorama confuso para la gestión de estas hipótesis complejas.

Enfocamos el estudio dentro del plano de la causalidad, debido a que permite analizar cómo se integran ciertos medios de prueba que tornan más compleja la argumentación del operador jurídico. En el caso de los campos electromagnéticos, cobran relevancia los estudios epidemiológicos, que conducen a un razonamiento causal no directo.

A los fines de ordenar el análisis, en primer término, se hace necesario presentar cuales son los insumos teóricos que nos permiten concretarlo. A esos efectos, utilizamos la construcción que, respecto de la lógica de ordenación y composición de los distintos dispositivos de tratamiento social del riesgo, presenta la obra de François Ewald. Tomamos estas descripciones como paradigmas, entendiendo por tales el conjunto de prácticas, discursos, combinaciones, respecto de los cuales es dable la identificación de una cierta racionalidad.

El mencionado autor refiere a tres grandes paradigmas: responsabilidad, solidaridad y seguridad, configurados como resultado de la combinación de dimensiones políticas, técnicas y filosóficas. Se observa, de este modo, que las medidas legislativas en cuanto a la responsabilidad, así como también su aplicación judicial, forman parte de esas mixturas. La opción por el uso de esta herramienta y la descripción de etapas históricas, se justifica a los efectos de mostrar aquellos elementos que resultan de utilidad para reflexionar sobre la composición del raciocinio que sustenta a cada uno de ellos. En relación a lo expuesto, y a título de advertencia, el referido autor realiza una aclaración de la cual nos apropiamos, en la que afirma

[...] si la presentación según un desarrollo histórico tiene sus virtudes pedagógicas, corre el riesgo de inducir al error en la medida en que conduce a pensar que todo se transformó al mismo tiempo. La sistematicidad

${ }^{17}$ EWALD, François. Le retour du malin génie. Esquisse d'une philosophie de la précaution. In: GODARD, Olivier (Dir.). Le principe de précaution dans la conduite des affaires humains Paris:Editorial de la Maison des Sciences de l'homme, 1997. 
necesaria en la exposición no lo es necesariamente en los hechos. Hay regímenes de responsabilidad diferentes según las especies, los casos, los dominios. Ellos tienen historias diferentes que no obedecen necesariamente a las mismas cronologías [...] (EWALD, 1992, p. 11).

Teniendo en consideración esta salvedad, la utilidad de trabajar a partir de esta genealogía se justifica en la consecuente posibilidad de elaborar un esquema que identifique las disímiles racionalidades y que permita la construcción de una herramienta de análisis.

El primer paradigma que presenta es el de la "responsabilidad", desarrollado a lo largo del siglo XIX, y basado en el adagio "pas de responsabilité sans faute”, que presupone la existencia de un sujeto que individualmente puede prever las consecuencias de sus actos, de las que debe hacerse cargo, configurando un sistema de prevención individual.

Dentro de la doctrina argentina, Lorenzetti efectúa una elaboración basada en las diferentes visiones esgrimidas en relación al derecho de daños. A medida que da cuenta de estas miradas, efectúa un análisis de los presupuestos de la responsabilidad y establece una distinción según se considere a la misma como deuda o como crédito. Consideramos que la idea de responsabilidad como deuda es compatible con el paradigma introducido. La responsabilidad civil, en este caso, es entendida como deuda a cargo del dañador y frente al dañado. La sanción y la reparación constituyen sus funciones esenciales. La finalidad punitiva - similar a la que tiene a cargo el derecho penal - conduce a su actuación de forma restrictiva, so pena de provocar su desnaturalización.

Se presentan como presupuestos trascendentes la acción humana y la antijuridicidad, lo cual puede visualizarse a partir de la lectura de la versión originaria del Código Civil argentino, en armonía con el conjunto de la codificación decimonónica.

Ahora bien, en relación al concepto de causalidad se infiere que el mismo no es central debido a que se encuentra muy vinculado al de autoría. Se trata de probar quien fue el autor de un daño utilizando un razonamiento basado en datos obtenidos de la realidad. Se establece una indagación hacia el pasado a los efectos de encadenar los hechos productores del perjuicio mediante la utilización de una lógica de tipo causa - efecto, la cual es reflejo del modo de pensar inscripto en el ámbito de las ciencias naturales. De este modo, el modelo de gestión de la causalidad se condice con la posibilidad de autorregulación de las conductas humanas. Las teorías que se elaboran respecto de la causalidad presentan un rasgo común debido a que consideran los datos verificables empíricamente a fin de establecer el vínculo causal.

El paradigma de "solidaridad", se inicia hacia fines del siglo XIX y se extiende durante el siglo XX. En éste se incorpora la noción de riesgo, y se expande la figura del seguro 
como técnica para efectuar la repartición de riesgos, en un contexto ligado a la utopía de una ciencia que cada día adquiere mayor capacidad de dominio respecto de los mismos. ${ }^{18}$

Lo expuesto da lugar a una escisión entre la idea de causalidad y la de imputación, debido a que ya no se visualiza la relación causal objetivamente, sino que se tienen en cuenta otros parámetros, “[...] lo cual conduce a cambiar la manera de pensar el problema de la imputación jurídica de los daños: no más en términos de causa, sino en términos de repartición $[\ldots]{ }^{\prime} .{ }^{19}$

En base a lo antedicho vislumbramos que el factor de atribución subjetivo pierde preponderancia en razón de la emergencia del factor atributivo de carácter objetivo, a través de la consolidación de figuras como el riesgo creado, la equidad, el abuso del derecho, la garantía. A su vez, se amplía el concepto de antijuridicidad, "[...] la doctrina coincide en calificar la conducta antijurídica como aquella que menosprecia al ordenamiento jurídico en su conjunto y no sólo a la ley [...]”' Lorenzetti, 1993, p. 1145.

En este marco, los presupuestos trascendentes son el daño, que conserva su requisito de certitud, y la relación de causalidad. Esta última, ya no se basa en un análisis retrospectivo a partir de datos reales, sino que incorpora la variable de regularidad, de normalidad de los acontecimientos, se habla de adecuación de la relación causal. Ahora bien, la gestión de la causalidad a partir de la noción de regularidad, también se torna inapropiada en relación al caso bajo análisis. Ello es así porque la imposibilidad de determinar la dañosidad de la generación de ondas electromagnéticas, genera que no existan criterios en base a los cuales sustentar la regularidad de su acaecimiento.

El tercer paradigma, que es el que nos ocupa, es el de "seguridad"20, cuya emergencia se observa hacia fines del siglo XX, asentado sobre la aparición de casos inmersos en un contexto de incerteza científica, en el que se destaca la posibilidad eventual de daños graves o irreversibles. La noción de irreversibilidad se encuentra ligada a la idea de desarrollo sustentable y, asimismo, plantea una reformulación respecto del daño. Ello se debe a que, en algunos supuestos, una vez acontecido el perjuicio no hay posibilidad de revertir sus efectos dañosos. Asimismo, pone al descubierto que existen menoscabos que no sólo no pueden ser compensados ni reparados sino que, además, no son valuables económicamente.

\footnotetext{
${ }_{18}$ EWALD, François. Le retour du malin génie. Esquisse d'une philosophie de la précaution. In: GODARD, Olivier (Dir.). Le principe de précaution dans la conduite des affaires humains Paris:Editorial de la Maison des Sciences de l'homme, 1997.

19 EWALD, François. Le retour du malin génie. Esquisse d'une philosophie de la précaution. In: GODARD, Olivier (Dir.). Le principe de précaution dans la conduite des affaires humains" Paris:Editorial de la Maison des Sciences de l'homme, 1997. p. 104

20 "Puede ser que en este fin del siglo XX estemos en tránsito hacia el nacimiento de un nuevo paradigma, que no ha encontrado todavía su propio nombre, pero sobre el cual ciertos signos testifican su llegada" EWALD, François. Philosophie de la précaution. L'Année sociologique, Paris, n. 46-2, 1996. p. 385.
} 
Se configura una vulnerabilidad antes desconocida para los individuos, un retorno a las catástrofes, pero ya no provenientes de la naturaleza, sino de la misma actividad del hombre ${ }^{21}$. Estos casos, generalmente vinculados al medio ambiente y a la salud humana, denotan la imposibilidad de su gestión mediante los mecanismos que brinda la noción de responsabilidad como dispositivo de prevención individual y colectiva, conforme a los dos paradigmas anteriores.

Dentro de estos supuestos, caracterizados por la incerteza en cuanto a su dañosidad, situamos el caso de los campos electromagnéticos emanados de la instalación de antenas de telefonía celular, ya que en éste no hay certeza sobre potenciales daños hacia la salud o el ambiente, y existe la posibilidad de que sus consecuencias hayan de constituirse como graves o irreversibles.

Frente a este tema, tanto las combinaciones subyacentes al paradigma de la responsabilidad como al de la solidaridad se encuentran excedidas. La idea de prevención individual basada en la noción de culpa no es adecuada. Por su parte, el esquema de prevención colectiva, en el que se desarrolla la figura del seguro como técnica de repartición, detenta una serie de dificultades que tienen que ver con la imposibilidad de funcionamiento de la técnica actuarial que lo sustenta. Ello se debe a que las hipótesis de hecho posiblemente riesgosas no ofrecen las notas de regularidad que requiere la estadística a los fines de establecer su calculabilidad. A su vez, la prevención en el sentido referenciado se torna difícil debido a la carencia de datos e información suficientes. La actitud preventiva puede sólo funcionar respecto de los riesgos previsibles; sus pilares constitutivos no le permiten dar cuenta de la incertidumbre.

Por lo expuesto, la emergencia de la lógica precautoria ${ }^{22}$ puede servir como marco para completar la tarea preventiva en casos en los que se trabaja en base a riesgos posibles y, por ende, imprevisibles.

La carencia de certezas no sólo sustenta la duda, sino que se aleja del plano de las evidencias. Es por ello que se afirma que el principio de precaución supone una nueva

${ }^{21}$ EWALD, François. Le retour du malin génie. Esquisse d'une philosophie de la précaution. In: GODARD, Olivier (Dir.). Le principe de précaution dans la conduite des affaires humains" Paris:Editorial de la Maison des Sciences de l'homme, 1997.

${ }^{22}$ Los basamentos filosóficos del principio precautorio han sido analizados por Hans Jonas en su obra "Le principe responsabilité". El autor divide la historia de la humanidad a partir de la ruptura entre mundo antiguo y mundo moderno, considerando que en la relación con la naturaleza se establece un pasaje del hombre como ser dentro de la naturaleza al hombre como dueño y señor de la misma, a partir del desarrollo de la ciencia y tecnología. El individuo adquiere una capacidad de destrucción, tanto de sí mismo como de su entorno, anteriormente desconocida, lo que genera el nacimiento de un nuevo concepto de responsabilidad acorde a ese poder ilimitado. Sostiene el autor que el ámbito ecológico es aquel en el cual se da lugar a las responsabilidades más extremas en un contexto de incertidumbres radicales. JONAS, Hans. Le principe responsabilité. Paris: Ed. du Cerf, 1990. 
relación respecto de la ciencia y el conocimiento y “[...] nos reenvía a un epistemología de la relatividad del conocimiento científico $[\ldots]$... ${ }^{23}$ Los casos a partir de los cuales se puede entrever esta nueva situación, son cuestiones respecto de las que no es posible aseverar acabadamente sus consecuencias.

Se conjuga la imposibilidad de determinación cierta sobre la dañosidad de una hipótesis de hecho, con el tema de la causalidad, constituyéndose éste como uno de los ejes que mayores complicaciones presenta. La incerteza ejerce gran influencia en el marco de la vinculación causal, así como también respecto de la existencia del daño.

En el primer caso, la carencia de certitudes no permite ni el establecimiento de una relación de causalidad basada en datos reales, ni tampoco en regularidades, debido a la falta de información que sustente el funcionamiento de la estadística. A su vez, ya no se puede referir a un daño cierto y conocido, sino que se trata de daños potenciales, posibles, "la hipótesis de precaución nos pone en presencia de un riesgo no mensurable, es decir no evaluable, es decir un no - riesgo". ${ }^{24}$

Lo expuesto conlleva a un necesario repensar de la gestión de este tipo de supuestos. A partir de ello, pueden plantearse diferentes alternativas, entre las cuales destacamos: a) la construcción de nuevos regímenes de causalidad ${ }^{25}$; b) la creación de nuevas herramientas de gestión del riesgo.

Dentro de la primera opción, aparecen nuevas elaboraciones sobre vínculos causales $^{26}$, que proponen dejar de lado la relación causal de tipo directa y de corte individualista, construida a manera de causa - efecto, y transformar la misma a partir de la incorporación de lo incierto en su seno constitutivo, recomponiendo el presupuesto de causalidad del derecho de daños.

\footnotetext{
${ }^{23}$ EWALD, François. Le retour du malin génie. Esquisse d'une philosophie de la précaution. In: GODARD, Olivier (Dir.). Le principe de précaution dans la conduite des affaires humains Paris:Editorial de la Maison des Sciences de l'homme, 1997. p.116.

${ }^{24}$ EWALD, François. Le retour du malin génie. Esquisse d'une philosophie de la précaution. In: GODARD, Olivier (Dir.). Le principe de précaution dans la conduite des affaires humains Paris:Editorial de la Maison des Sciences de l'homme, 1997. p. 113.

25 “[...] notre époque abonde en illustrations de causalité complexe [...] " THIBIERGE, Catherine. Libres propos sur le droit de la responsabilité. Vers un élargissement de la fonction de la responsabilité civile? Revue Trimestral de Droit Civile, Paris, Jui./Sep. 1999. p. 568.

${ }^{26}$ Entre éstas mencionamos la causalidad distendida, que revela la prolongación del tiempo existente entre el hecho generador y el daño, lo que supone tener en cuenta el factor tiempo y la noción de generaciones futuras, así como también una reflexión sobre el concepto de prescripción; la causalidad multiplicadora a partir de la cual un pequeño hecho generador puede desencadenar grandes efectos por reacción en cadena; la causalidad diluida que da cuenta de la dificultad en la identificación del generador del daño; la causalidad circular que pone en acento en la inseparabilidad e interdependencia de los factores de riesgo; la causalidad probable que tiene en cuenta las incertezas científicas; la causalidad insospechada desconocida en principio y revelada luego, considerando el tópico del riesgo del desarrollo (THIBIERGE, 1999).
} 
Por otra parte, y ante el referido panorama, se da lugar a otra posibilidad que propone la generación de una herramienta de gobierno del riesgo, ya no mediante la transformación del derecho de daños, sino mediante la creación de nuevos mecanismos de gestión. A través de los mismos - y dentro de un escenario en el cual se ha puesto al descubierto la relatividad del conocimiento científico y su consecuente imposibilidad de dominio absoluto respecto del riesgo - cabe asignar trascendencia a la duda, a las opiniones disidentes, a la integración de conocimientos provenientes de disciplinas diversas pero convergentes en torno a una problemática determinada.

En consonancia con lo antedicho se sostiene que el derecho de daños, y aquí pensamos en los daños ambientales y en los daños a la salud, no cuenta con plasticidad suficiente para gestionar de forma adecuada las hipótesis de hecho cuyas consecuencias son desconocidas, la "[...] incerteza científica que no puede ser abordada desde este sistema jurídico pensado para que la ciencia establezca las causalidades [...]". ${ }^{27}$

Se trata, entonces, de repensar la relación entre los postulados de la ciencia y el derecho. Tornándose inadecuado el razonamiento científico de tipo causa - efecto, ya no puede sucederle una argumentación jurídica de ese mismo tenor. Lo expuesto no significa que la aplicación de la lógica precautoria configure un "principio anticientífico", por el contrario, la necesidad de rigor científico se consubstancia con el principio de precaución, así como también éste aumenta la necesidad de un procedimiento científico. ${ }^{28}$ Se trata de detectar la posible hipótesis dañosa y, luego, direccionar y organizar los mecanismos necesarios a fin de profundizar el conocimiento disponible a su respecto. De tal modo,

[...] Destinado a racionalizar el expertise científico y la decisión política en un período de incertitudes y de controversias científicas, el principio de precaución...impone la evaluación científica de riesgos sospechados $[\ldots] .^{29}$

Este principio implica, entonces, la puesta en marcha de acciones de investigación pertinentes ${ }^{30}$. Se trata de poner a disposición los recursos necesarios para el

${ }^{27}$ SOZZO, Gonzalo. Riesgos del desarrollo y sistema del derecho de daños (hacia un derecho de daños pluralista). In: DIREITO, sociedade e riscos. A sociedade contemporânea vista a partir da idéia de risco. Red Latino - Americana e Européia sobre Governo dos Riscos. Brasilia: [s.n.], 2006. p. 312.

${ }^{28}$ NOIVILLE, Christine. Science, décision, action: trois remarques à propos du principe de précaution. Petites affiches, Paris, n. 218-219, $1^{\mathrm{er}}-2$ nov. 2004

${ }^{29}$ HERMITTE, Marie-Angèle. La fondation juridique d'une société des sciences et des Techniques par les crises et les risques. Paris: [S.n.], 2006/7. Material del Seminario "Droit des sciences et techniques" dictado en la EHESS. 2006. p.13

${ }^{30}$ Lo campos de investigación estarán guiados por una reflexión nacional. Sin perjuicio de ello, los autores del Rapport au Premier Ministre sobre el principio de precaución - que fuera presentado en Francia en 1999 -, afirman que existen algunos dominios que son evidentemente pertinentes como la epidemiología, la toxicología, el impacto de sustancias químicas sobre el medio ambiente, la salud y los ecosistemas. A lo cual agregan la posibilidad de estudiar acerca de la fiabilidad de ciertos sistemas complejos como la aviación civil, o analizar la percepción del riesgo (KOURILSKY; VINEY, 1999). 
caso en que haya una crisis, lo cual puede ser organizado mediante la formación de fondos de intervención. ${ }^{31}$

Dentro de esta lógica de confluencia de saberes en torno a una problemática, podemos acercarnos también a la idea - aunque marginal o minoritaria - de la precaución como pasible de conceder importancia a los argumentos disidentes o marginales, e incluso a razonamientos provenientes de otros marcos.

Luego de la presentación del paradigma de seguridad como adecuado para la gestión de riesgos inciertos, podemos señalar que cada paradigma se configura como resultado de la combinación de dimensiones políticas, técnicas y filosóficas.

De este modo, las medidas legislativas en relación al caso, así como también su aplicación judicial, forman parte de esas mixturas y nos permiten realizar su análisis a partir de su racionalidad fundadora, detectando si se basan en la idea de responsabilidad, de solidaridad o de seguridad.

Es nuestra tesis que, si bien el caso de la instalación de antenas de telefonía celular puede encuadrarse dentro del marco de una "situación de precaución" 32 , a partir de los discursos de los actores sociales intervinientes emerge un panorama en el que se conjugan elementos de los diversos paradigmas de tratamiento social del riesgo.

\subsection{De las lógicas que subyacen al caso de la instalación de antenas de telefonía celular, una mirada a partir de la jurisprudencia y la normativa aplicable. Hacia una ampliación de la hipótesis: sobre los efectos de la positivización del principio precautorio en Argentina}

En este apartado nos proponemos efectuar un acercamiento sobre la manera a través de la cual se articulan las nociones precedentes en el caso concreto de la instalación de antenas de telefonía celular.

Si bien la racionalidad que subyace al principio precautorio sería propicia para coadyuvar a la gestión de esta hipótesis, en base a las normas jurídicas y jurisprudencia en la materia, detectamos la emergencia de racionalidades disímiles que generan un panorama complejo y desordenado.

Asimismo, como ampliación y complejización de esta tesis, sostenemos que la promulgación - en fecha 27 de noviembre de 2002 - de la Ley de Política Ambiental N ${ }^{\circ} 25.675$

${ }^{31}$ KOURILSKY, Philippe; VINEY, Genevieve. Le principe de précaution. Rapport au Premier Ministre. Paris: Ed. Odile Jacob, 1999. (La documentation Française). 1999. p. 98.

32 “"...] Una situación de precaución implica al menos: el productor del riesgo, el regulador, la víctima, pero así también el experto, el periodista, que tienen a su cargo la tarea de medir, de evaluar los riesgos como de informar [...]" EWALD, François. Le principe de précaution. Que sais je? Paris: PUF, 2001. p. 70. 
detenta especial relevancia dentro de este panorama, en razón de que la misma incorpora en su artículo 4, como principio de política ambiental, el precautorio:

Cuando haya peligro de daño grave o irreversible la ausencia de información o certeza científica no deberá utilizarse como razón para postergar la adopción de medidas eficaces en función de los costos, para impedir la degradación del medio ambiente.

Uno de los efectos de esta positivización es la consecuente configuración del conjunto de casos a los que el operador judicial estima como ámbito de aplicación.

A tenor de lo expresado en la normativa, el mismo sería aplicable a supuestos de posible degradación del medio ambiente ante la existencia de un peligro grave o irreversible y desconocido científicamente.

Ahora bien, ¿es el caso de los campos electromagnéticos un supuesto de daño ambiental o de daño a la salud?; es decir ¿se trata de un caso de daño ambiental directo, indirecto o ambos a la vez?

A lo cual agregamos, ¿el daño a la salud se haya comprendido en el marco del daño ambiental?

A partir de la lectura de los decisorios judiciales sostenemos que la sanción de la Ley de Política Ambiental, ha coadyuvado a la aplicación del principio precautorio en aquellos casos en los que el operador judicial plantea el posible daño como atentatorio respecto del medio ambiente ${ }^{33}$.

Lo expuesto se desprende de las fechas de las resoluciones judiciales: los fallos en que se hace referencia al principio son posteriores a la promulgación de la ley; sus argumentos, primordialmente, enfocan el caso como ambiental.

Por otra parte, en los procesos en que la temática llevada a instancia judicial se considera primordialmente como daño a la salud humana - dentro de los cuales uno de ellos es previo a la sanción de la ley de Política Ambiental -, no se hace aplicación de éste y se pueden

${ }^{33}$ El tratamiento diferencial asignado a los casos medioambientales puede relacionarse con las notas características bajo las que se construye el derecho ambiental. Éste "[...] es claramente un derecho que abandona este paradigma moderno o por lo menos procura evitarlo, por resultar directamente disfuncional a sus objetivos primarios. Es un derecho que no emplea la lógica de atribución contractual sino a través de la herencia intergeneracional; admite sujetos colectivos y futuros como las generaciones futuras; abandona la idea moderna del tiempo, vinculando directamente al futuro en las decisiones presentes; abandona la distinción moderna hombre/naturaleza para admitir la noción de una naturaleza tecnificada; admite la limitación de la ciencias; abandona la idea de causalidad adecuada; procura construir un sistema que asegure la precaución y la reparación en especie (recomposición) [...] el Derecho ambiental está pensado desde la perspectiva de lo colectivo [...]" SOZZO, Gonzalo. Riesgos del desarrollo y sistema del derecho de daños (hacia un derecho de daños pluralista). In: DIREITO, sociedade e riscos. A sociedade contemporânea vista a partir da idéia de risco. Red Latino - Americana e Européia sobre Governo dos Riscos. Brasilia: [s.n.], 2006, p. 326. 
identificar con mayor facilidad elementos que son propios de lógicas anteriores del derecho de daños.

\subsubsection{Primer caso: “Alguna Referencia” A la noción de precaución. Trascendencia de las "Pruebas Científico - Técnicas". Segundo caso: renovada referencia a la noción de precaución, renovada trascendencia de las "Pruebas Científicos - Técnicas"}

El Juzgado de Primera Instancia en lo Contencioso, Administrativo y Tributario Número 12 de la Ciudad Autónoma de Buenos Aires, en fecha 18.10.06, resuelve sobre la medida cautelar planteada por el amparista en el caso "Peino, Leonardo Esteban y otros c/ GCBA sobre amparo (Art. 14 CCABA)".

En la resolución, posterior a la promulgación de la Ley de Política Ambiental, si bien se hace referencia al principio precautorio, no es éste el argumento principal en base al cual se funda el decisorio.

El proceso se inicia a partir de la interposición de una acción de amparo por parte de un grupo de padres de los alumnos del Colegio "San José de la Palabra de Dios" contra el gobierno de la ciudad autónoma de Buenos Aires. Éstos solicitan se arbitren los medios necesarios para suspender el funcionamiento de una antena de telefonía móvil instalada sobre el techo del establecimiento educativo. La misma fue emplazada en el año 2000, en razón de la firma de un contrato entre la empresa Telecom S.A. y las autoridades del Colegio, según el cual, a cambio de la autorización para instalar la antena, la escuela recibe mil quinientos pesos mensuales.

Los padres de algunos de los alumnos comenzaron a preocuparse por la situación $\mathrm{y}$, como primera medida, se juntaron doscientas cincuenta firmas a los efectos de peticionar que se retire el equipo. Ante lo infructuoso de esa tentativa, siete padres presentaron una acción de amparo contra el gobierno de la ciudad, que es quien tiene a cargo el tema del emplazamiento de las antenas de telefonía móvil. La preocupación por la temática, según afirmaciones de la madre de uno de los alumnos, “[...] explotó en marzo, cuando nos enteramos que un ex alumno y una ex alumna de $5^{\circ}$ año tuvieron leucemia, y que un profesor también padece cáncer [...]". Respecto de ello afirma otro de los padres que

[...] Es muy difícil poder determinar si realmente las ondas electromagnéticas incidieron en esa enfermedad. Habría que hacer una investigación mucho más profunda. No estoy diciendo que antena sea igual a cáncer. Pero si la presunción de que puede hacer daño existe, entonces hay que sacarla $[\ldots]^{34}$.

\footnotetext{
${ }^{34}$ A SACAR las ondas del colegio. El Diario, 26 oct. 2006. p. 12.
} 
Llegados a la instancia judicial los actores fundan su petición en dos conceptos. El primero, la aplicabilidad al caso del principio de precaución; el segundo, el incumplimiento por parte de la empresa de presentar en legal tiempo y forma el informe de evaluación de impacto ambiental y social (EIAS) y la falta de control por parte del gobierno local de tal procedimiento. Asimismo, solicitan que como medida cautelar se ordene la desconexión de la antena de referencia, hasta tanto se resuelva sobre el fondo de la cuestión.

Al momento de pronunciarse sobre la medida cautelar solicitada, si bien el juez menciona la idea de precaución, se basa prioritariamente en la falta de presentación acabada de la EIAS. Decide

[...] Hacer lugar a la medida cautelar peticionada y en consecuencia, ordenar al GCBA a que, por conducto del Ministerio de Medio Ambiente, arbitre los medios para que se suspenda el funcionamiento de la antena de telefonía celular...hasta tanto se resuelva sobre el fondo de la presente acción de amparo, o bien hasta que se acredite en autos que se ha cumplido acabadamente con el procedimiento de evaluación de impacto ambiental y la Autoridad ambiental haya extendido la pertinente autorización [...].

Ahora bien, en base a las notas características del instituto de evaluación de impacto ambiental, podemos concluir que se advierte cierta dificultad al momento de su empleo para esta hipótesis de hecho cuyas consecuencias dañosas son indeterminadas.

Esta herramienta se configura como evaluación previa a la instalación de un proyecto susceptible de dañar el medio ambiente o la salud. El tribunal, entiende que

[...] No está de más recordar que la evaluación de impacto ambiental "puede ser definida en su formulación moderna como un proceso por el cual una acción que debe ser aprobada por una autoridad pública y que puede dar lugar a efectos colaterales significativos para el medio, se somete a una evaluación sistemática cuyos resultados son tenidos en cuenta por la autoridad competente para conceder o no su aprobación" (Lee "Environmental Impact Assestment: A Rewiew, citado por Ramón Martín Mateo en Tratado de Derecho Ambiental, Ed. Trivium, España, 1991, T IV, p. 302).

Ahora bien, en el caso bajo análisis se torna compleja la determinación del daño que pudiera ocasionarse respecto del medio ambiente o la calidad de vida de la población, debido a que no existe certeza acerca de la potencial dañosidad del emprendimiento. Sin perjuicio de estas disgreciones, el juez considera que

[...] todo emprendimiento que pudiera ser susceptible de generar alteraciones o perjuicios degradantes al entorno en el futuro debe encontrar límites jurídicos razonables, y la herramienta predictiva llamada a determinarlos es la evaluación de impacto ambiental...La carencia de tal instrumento hace imposible predecir los efectos que la ejecución del proyecto tendrá sobre los componentes del medio [...]. 
A lo expuesto agrega que

[...] el procedimiento administrativo de evaluación de impacto ambiental resulta ser una prueba cabal a la hora de ponderar los efectos que un determinado emprendimiento causará en el entorno [...].

Los caracteres de "herramienta predictiva" y de "prueba cabal" asignados a este instrumento parecen sobredimensionarlo, sobre todo en consonancia con el escenario de incertidumbre en el que se despliega el tema de los campos electromagnéticos. Sin perjuicio de ello, se trata de un procedimiento técnico - jurídico útil y extendido, pero cuya efectividad nos parece más acabada respecto de los casos de emprendimientos generadores de consecuencias dañosas ciertas para el entorno. Esta valoración es observable dentro de la misma línea argumentativa en la cual se afirma que "[...] Se desconoce por completo qué consecuencias disvaliosas sobre el ambiente puede generar la antena que se encuentra funcionando sobre un establecimiento escolar [...]".

De lo expuesto se extrae que, si bien se mencionan elementos que subyacen al pensamiento precautorio, se lo hace de manera periférica. Se nombra la existencia del principio y su recepción en el artículo 4 de la Ley General del Ambiente en su considerando número I, que remite a las afirmaciones sostenidas por la actora.

Por otra parte, visualizamos que en la argumentación principal se hace referencia al supuesto de hecho como un caso de índole ambiental. Se resalta fundamentalmente la necesidad de previsión acerca de la incidencia que el proyecto ocasiona para el entorno. Visualizamos, entonces, que se inscribe el decisorio en el plano de la evaluación de impacto ambiental, centrándose los argumentos en la falta de presentación completa de la misma.

Ello deja traslucir la relevancia que se asigna al discurso experto en la materia que se patentiza en el contenido de este tipo de procedimiento. El mismo, según lo expresado por el juez, hace las veces de "prueba por antonomasia" debido a que

[...] considerando que nos encontramos frente a un amparo ambiental, en el que las pruebas por antonomasia son las periciales científico - técnicas, las que una vez realizadas darán a la suscripta andamiaje suficiente como para resolver si la antena en cuestión produce efectos contaminantes [...].

El mismo Juzgado, en fecha 18.09.07, dicta un nuevo fallo en autos caratulados "Uyemas, Héctor Ubaldo c/ GCBA s/ Amparo (Art. 14 CCABA)" sobre un supuesto de hecho similar en el que renueva su referencia al principio de precaución y a la trascendencia de las "pruebas científico - técnicas".

El amparo es incoado por un vecino de un edificio en cuya azotea se halla emplazada una antena de telefonía celular. El actor solicita, que como medida cautelar se ordene la desconexión de la misma, fundándose en la aplicabilidad del principio precautorio, dados los eventuales efectos cancerígenos de los campos electromagnéticos que ésta genera. Asimismo, 
se basa en la no finalización del procedimiento de Evaluación de Impacto Ambiental y Social (EIAS), que es obligatorio según la normativa aplicable.

En su resolución el a quo retoma los argumentos utilizados en el caso "Peino", es así como afirma que "[...] evaluación de impacto ambiental no fue realizada y, por ende, se desconocen los efectos que la antena puede generar [...]”; "[...] la carencia del EIA me inclina a otorgar la cautela solicitada [...]".

Observamos que se asigna al caso carácter ambiental, se habla de "amparo de naturaleza ambiental" y se vuelve a otorgar gran trascendencia al procedimiento científico técnico de EIAS, al cual se le asigna el rol de "prueba por antonomasia".

Pero, a diferencia del fallo anterior, en esta segunda sentencia, se hace referencia directa e indirectamente al principio de precaución en la argumentación. Se cita expresamente el texto del art. 4 de la Ley 25.675/02 y, luego, se remite a jurisprudencia de la Cámara Federal de la Plata Sala I - de fecha 28.06.07, “Telefónica Comunicaciones Personas S.A. c/ Municipalidad de Lanús s/ acción declarativa de inconstitucionalidad”, que reitera la conceptualización de este principio:

[...] La falta de certeza científica no puede utilizarse como razón para postergar la adopción e impedir la degradación del ambiente cuando haya peligro de un daño grave e irreversible [...]. Asimismo dispuso

"Revocar la medida cautelar dispuesta, hasta tanto la empresa accionante acompañe un informe detallado sobre la potencial nocividad de los campos electromagnéticos generados sin permiso [...].

La precedente observación, permite vislumbrar un acercamiento más decidido en relación a la racionalidad precautoria, que se refuerza con afirmaciones tales como

[...] adquiere relevancia la mutación que sufre el proceso en orden a las transformaciones que impone el derecho ambiental...”, “...la verosimilitud en el derecho será analizada bajo un prisma no tan riguroso, admitiéndose medidas precautorias en materia ambiental, aún cuando no exista una certeza científica sobre los efectos perjudiciales cuya producción quiera prevenirse en esta materia [...].

\subsubsection{De inmisiones inmateriales ¿Adecuación del Art. 2618 del Código Civil al tratamiento del caso?}

El tercer supuesto en relación al tema de la instalación de antenas de telefonía celular es "Espíndola María c/ Movicom Bellsouth s/ Daños Perjuicios" del Juzgado Civil de Primera Instancia $\mathrm{N}^{\circ} 105$ de la localidad de José C. Paz, de fecha 09.02.07.

En esta resolución, también posterior a la promulgación de la Ley de Política Ambiental, se hace lugar a la demanda y se ordena a la demandada abonar una indemnización por daño moral, por daños potenciales a la salud y por daño material, así como también se impone a 
[...] la COMPAÑIIA DE TELECOMUNICACIONES MOVILES (ahora Telefónica Móviles Argentina S.A.) y a la MUNICIPALIDAD DE JOSE C. PAZ, en forma solidaria el desmantelamiento total de la torre autosoportada, la antena y demás instalaciones sita en calle Lavalle 2903 de la localidad de José C. Paz Prov. De Buenos Aires, en el plazo máximo de noventa (90) días de quedar firme este pronunciamiento [...].

La actora planteó que

[...] Desde hace cinco años la codemandada Movicom, supuesta titular del inmueble lindero al domicilio de la actora, instaló en el límite con la propiedad de su mandante una torre gigantesca de aproximadamente 50 $\mathrm{m}$. de altura que tiene motores y otros elementos que ocasionan molestias $\mathrm{y}$ ruidos intensos y permanentes en forma continua e intermitentemente, dado que el motor enciende y apaga en forma automática durante las 24 hs del día. Agrega que la antena interfiere con aparatos eléctricos y/o electrodomésticos de la vivienda, produciendo además de ruidos molestos, luces intensas y gases por el aire que despide un equipo instalado en dicha torre. Sigue relatando que la actora es una persona no vidente, y que muy a menudo concurre personal de mantenimiento, que sube a la torre con herramientas, algunas de las cuales a veces caen en terreno de propiedad de la actora $[\ldots]$.

En razón de lo expuesto, es que la señora Espíndola interpone demanda por daños y perjuicios, tanto contra la empresa Movicom Bellsouth, como contra la Municipalidad de José C. Paz. Asimismo, solicita que se ordene la remoción de la antena “...para evitar se continúen causando daños [...] funda su reclamo en los términos del art. 2618 del Código Civil [...]"35.

La actora pretende, en base a este fundamento legal, por un lado, una indemnización por los daños ocasionados y, por el otro, la cesación del funcionamiento de la antena debido a las inmisiones inmateriales que de ella se derivan. Específicamente, hace hincapié en el ruido que de la misma proviene, lo cual en el caso se agrava por dos razones: la cercanía del soporte de la antena a su inmueble - menos de un metro - y las condiciones particulares de la perjudicada, que es no vidente y transita su mayoría de edad.

En los argumentos elaborados por ambas partes demandadas, vislumbramos un concepto formal de antijuridicidad. En este supuesto, la trascendencia otorgada a estas argumentaciones es llamativa debido a que el citado art. 2618 es uno de los pocos dispositivos que, en la legislación civil, presenta explícitamente la posibilidad de atribución de responsabilidad sin mediar antijuridicidad formal. Se puede responsabilizar al agente prescindiendo de la existencia

\footnotetext{
${ }^{35}$ El artículo 2618 del C. C. expresa: "Las molestias que ocasionen el humo, calor, olores, luminosidad, ruidos, vibraciones o daños similares por el ejercicio de actividades en inmuebles vecinos, no deben exceder de la normal tolerancia teniendo en cuenta las condiciones del lugar y aunque mediare autorización administrativa para aquellas. Según las circunstancias del caso, los jueces pueden disponer la indemnización de los daños o la cesación de tales molestias. En la aplicación de esta disposición el juez debe contemporizar las exigencias de la producción y el respeto debido al uso regular de la propiedad; asimismo tendrá en cuenta la prioridad en el uso. El juicio tramitará sumariamente".
} 
de autorización administrativa para funcionar, “[...] Esta responsabilidad existe como excepción a la regla que dispone que no hay deber de reparar sin antijuridicidad. Su base está en el daño causado [...]" Mosset Iturraspe (1997, p. 90).

Sin perjuicio de ello, la compañía de telefonía móvil sustenta su defensa en la iniciación en tiempo y forma de los trámites requeridos por la Municipalidad de José C. Paz - organismo competente en razón de la ubicación territorial en que se encuentra la antena -; y en la autorización que obtuvo de parte de la Comisión Nacional de Comunicaciones, así como también en el cumplimiento de toda la normativa vigente en relación al tema.

La Municipalidad de José C. Paz, por su parte, argumenta que no se ha otorgado habilitación ni permiso alguno para la mentada instalación. Se destacan en la sentencia los requisitos que deberían haberse cumplimentado de conformidad a lo establecido por la Ordenanza 392/2002 de la Municipalidad de José C. Paz. De entre ellos, es loable remarcar la existencia de algunos parámetros novedosos, como la necesidad de presentar la autorización de los vecinos linderos y de los comprendidos en el radio que iguale la altura máxima del dispositivo medido desde su base; así como también la conformidad expresa de los propietarios o copropietarios en casos de instalaciones sobre azoteas o edificios preexistentes.

En el caso bajo análisis, no se contaba con la autorización de los vecinos linderos, siendo la actora uno de ellos.

A su vez, como instrumentos preventivos, se prevé la presentación de un estudio de impacto ambiental, otorgado por ente oficial, con las correspondientes medidas de mitigación; y la contratación de un seguro que cubra los eventuales daños por responsabilidad civil una vez que haya sido aprobada la prefactibilidad y emplazado el dispositivo.

En el proceso, la empresa demandada no prueba que se haya cumplido con requisito alguno de los precedentemente citados. Solamente ha efectuado un Pedido de Prefactibilidad, careciendo de todas las demás exigencias a cumplimentarse a efectos de obtener la autorización.

De un análisis del texto de la sentencia, obtenemos que si bien el caso podría haberse encuadrado dentro del marco del principio precautorio, el mismo no es introducido por la actora. Por el contrario, el argumento preponderante en la demanda se relaciona con las molestias que genera el funcionamiento de la antena, que exceden de la normal tolerancia y que por tanto deben ser detenidas.

Frente al contenido del planteo, el juez, en aplicación de la regla "iura novit curia" establece que

[...] aún cuando la actora, no hubo planteado en autos, el daño potencial que surge de la exposición permanente a la radiación electromagnética, 
las que aún por debajo de los límites permitidos en la legislación vigente, resultan potencialmente peligrosos. Conclusiones a las que han arribado, en múltiples Tribunales la de Unión Europea, que han establecido el daño potencial en la salud por la exposición permanente a radiaciones no ionizantes de instalaciones de telefonía móvil. Como así también, la Organización Mundial de la Salud (OMS), prevé establecer para el año 2007 un Protocolo que establezca el límite de radiaciones no ionizantes de telefonía móvil y de todo tipo de campos electromagnéticos, por debajo de las permitidas actualmente por las normativas vigentes a nivel mundial. Esto es por considerarlas, a dichas radiaciones nocivas para la salud, con efectos que se prolongan en el tiempo y que se manifiestan en daños genéticos, según datos estadísticos manejados por la OMS [...].

Del parágrafo anterior, obtenemos que el juez, en su sentencia, introduce la idea de incerteza respecto de la dañosidad de la hipótesis de hecho bajo análisis. Ahora bien, no se hace mención explícita del principio de precaución, si bien puede entreverse que su lógica subyacente es visualizable en el párrafo transcripto.

De lo antedicho, se podría desprender que la estructura el artículo 2618 del Código Civil como fundamento la demanda, se ve desbordada por este supuesto. La racionalidad constitutiva del texto legal no está pensada para aquellos casos en los que media una situación de incerteza; sino que se constituye como norma de carácter preventivo, actualmente ubicada como herramienta de tutela inhibitoria dentro del derecho de fondo.

\subsubsection{El Principio Precautorio no es aplicable}

Por último, analizamos dos casos referidos a similares hipótesis de hecho en los cuales no se hizo aplicación del principio precautorio.

Destacamos que, en ambos, los argumentos esenciales dan cuenta de sendos supuestos de hecho como daños a la salud, siendo el primero de los fallos anterior a la sanción de la Ley de Política Ambiental y el segundo posterior a la misma.

El primer caso, "Farina, Pablo M. c/ Compañía de Radiocomunicaciones Móviles S.A. s/ Acción de Amparo", fue objeto de resolución por parte de la Sala II de la Cámara Civil y Comercial de de la ciudad de Santa Fe, en fecha 04.05.01.

Se presenta una acción de amparo contra una compañía de telefonía móvil que pretende instalar una antena y su sala de equipamiento en un inmueble de la localidad de Coronda.

El actor es vecino del predio lindero, y padece de una enfermedad congénita que lo obliga al uso de audífonos. Este hecho no es menor dado que se considera la posible interferencia que el funcionamiento de la antena podría generar en el aparato. El demandante introduce en su pretensión la aplicabilidad del principio precautorio como sustento para impedir el emplazamiento, estableciendo incluso un concepto del mismo, que postula 
[...] que si una obra, tecnología o emprendimiento no puede garantizar en forma absoluta e indubitable la inocuidad del mismo para el entorno, la salud y calidad de vida, se debe dejar de lado [...].

A su vez, señala la omisión de la presentación de la evaluación de impacto ambiental, considerando que

[...] el estudio de impacto ambiental omitido, es mucho más que un informe técnico de un aspecto de la problemática, entrando en él otras variables que deben ser analizadas desde una óptica interdisciplinaria, con participación de biólogos, urbanistas, médicos, abogados y toda otra disciplina científica con competencia en el tema [...].

Por otra parte, destacamos que en el presente caso el actor hace referencia a la figura del seguro. Este dato nos parece interesante porque deja traslucir la incompatibilidad de este instituto respecto de la hipótesis de hecho. Afirma el demandante en su escrito inicial que

[...] Compañías alemanas de seguros como Allianz han reaccionado frente a esto ya que desde el año 1993 excluyen de sus seguros la cobertura por "riesgos de radiaciones electromagnéticas"..."; lo cual es reiterado nuevamente "...Ya hay compañías que excluyen de sus contratos los riesgos derivados de las radiaciones electromagnéticas (Lloyds, Sterling, Swiss RE, Allianz) [...].

Estas aseveraciones nos permiten vislumbrar la distinción entre riesgos previsibles y no previsibles. En el primer caso es factible el funcionamiento de la figura del seguro, dentro del paradigma de la solidaridad. Si el riesgo puede ser previsto, significa que hay un índice de ocurrencia, de regularidad que puede ser aprehendido y analizado por la técnica actuarial, como tecnología imbrincada en la base del contrato de seguro.El supuesto de los campos electromagnéticos se desarrolla dentro de un escenario incierto, es decir que no hay posibilidades de determinar fehacientemente su dañosidad, ni se dispone de datos suficientes para realizar cálculos actuariales.

Estas observaciones nos permiten entrever de qué manera las figuras que son previstas para un tipo de caso no pueden ser trasladadas fácilmente a situaciones que responden a otras realidades subyacentes.

En las hipótesis de precaución nos hallamos dentro del orden de lo ilimitado, no sólo de lo indefinido sino de lo indefinible, lo cual puede ser el fundamento de la actitud de algunos aseguradores en cuanto a las posibilidades de cubrir este tipo de daños potenciales. ${ }^{36}$

Por la otra parte, el sustento de la posición de la demandada se basa en el cumplimiento de la normativa aplicable al caso. En consonancia con lo antedicho se señala que

${ }^{36}$ EWALD, François. Philosophie de la précaution. L'Année sociologique, Paris, n. 46-2, 1996. 
[...] las antenas analizadas...respetan holgadamente los valores máximos tolerados, tanto nacionales como internacionales, por lo cual no puede afirmarse válidamente que presenten un riesgo para la salud de la población $[\ldots]$.

Además, se establece que la empresa ha procedido en todo momento de conformidad a las normas legales y reglamentarias aplicables. Ello denota la trascendencia que se otorga a la juridicidad de la acción llevada a cabo, debido a que se cuenta con la debida autorización administrativa para funcionar.

Al momento de la resolución, de los argumentos precedentes se descarta la aplicabilidad del principio de precaución y se adopta una postura tolerante respecto de la consecución de la actividad generadora de radiaciones ionizantes.

Lo expuesto, puede ser relacionado con la óptica que se atribuye al supuesto de hecho por parte del operador judicial, debido a que dentro de los argumentos detenta mayor relevancia la consideración del caso como supuesto de daño a la salud y no de daño ambiental. Por otra parte, también destacamos que la lógica precautoria no se encontraba positivizada al momento del dictado de la sentencia.

Lo antedicho, se desprende del discurso del Juzgado de Primera Instancia que establece que

[...] no puede afirmarse que la obra constituya para Farina una amenaza cierta y grave a su salud y vida de relación. Para así concluirlo debo necesariamente remitir al informe elaborado por la UTN...las mediciones efectuadas indican fehacientemente que todos están muy pro debajo del límite máximo establecido por el Estándart Nacional de Seguridad...a la que adhirió la provincia mediante decreto [...], [...] el perjuicio que se invoca no se da en el contexto de una ilegitimidad manifiesta, pues la resolución - no impugnada no aparece manifiestamente arbitraria o ilegal, única forma - además - en que podría adentrarse en el análisis de su razonabilidad o conveniencia [...].

En base a esos argumentos se rechaza el amparo, lo cual es confirmado por la alzada, quien sostiene que

[...] en la especie los parámetros señalados por la recurrente, no se han acreditado y por lo tanto la solución resulta la expuesta, porque de lo contrario todos los reparos que movieron a la misma a recurrir en la forma en que lo efectuaran, si fueran reconocidos en esta con base en la irrazonabilidad de la instalación, en la aplicación del principio de precaución, en su manifiesta ilegitimidad, en la falta de certeza absoluta, no respondería a un juez antiformalista, sino a uno arbitrario, desde que su decisión se asentaría en su sola voluntad, cuestión reprochable y, no en el consejo de los expertos que es el que debe seguirse cuando su ciencia no abarca dichos conocimientos [...].

Se interpreta que ante el escenario de incertidumbre científica, el juez no tiene posibilidad de adoptar una decisión, debido a que no cuenta con el respaldo que le otorga el 
dictamen experto en la materia. En ambas instancias se hace referencia a la trascendencia del conocimiento experto. En la primera resolución se afirma que

[...] como lo expresan los mismos letrados que promovieron la acción, las consecuencias negativas de la telefonía móvil o celular es un "tema en discusión" en los ambientes científicos como lo son otras tantas cuestiones vinculadas con el deterioro ambiental y su incidencia en la salud de la población...la única prueba fehaciente es el referido dictamen que, por provenir de expertos calificados con el respaldo de una institución universitaria, no puede ser desatendido $[\ldots]$.

De modo concordante, en la segunda instancia, se asevera que

[...] no aparece que la instalación de la antena....afecte la salud del actor, ni el equilibrio ambiental, protegidos constitucionalmente (art. $41 \mathrm{CN}$ ) ya que uno de los principios rectores del derecho ambiental, esto es, el de la realidad, atendiendo a lo informado en la pericia técnica, realizada por el Grupo de Investigación de Sistema Eléctricos de Potencia de la UTN [...]; [...] el derecho a un ambiente sano debe necesariamente ponderarse a partir de aquellos límites señalados técnicamente $[\ldots] ;[\ldots]$ ingeniero Walter Jiménez, investigador integrante del 'Grupo de Investigación' de “Sistemas Eléctricos de Potencia (GISEP) de la Facultad Regional Santa Fe de la UTN...refiriera que los niveles de densidad que han medido, son los adecuados, inferiores a los ponderados por la FCC de Estados Unidos [...] no pudiendo afirmar que el valor entendido como densidad de potencia sea perjudicial o no para la salud, porque es ingeniero, destacando que ni aún la Organización Mundial de la Salud lo puede hacer, ya que aún están desarrollando estudios epidemiológicos que terminarán dentro de tres o cuatro años [...].

No se da relevancia, en la fundamentación del fallo, a otros criterios. De hecho, en la sentencia de primera instancia si bien se hace referencia a otros marcos, no se los tiene en cuenta como susceptibles de coadyuvar a determinar la decisión.

Reza el a quo que

[...] la falta de planificación territorial y previsión colectiva a la hora de autorizar o consentir el proceso de ocupación física del espacio urbano ha determinado que todos padezcamos sino una amenaza grave a la salud, al menos una "verdadera contaminación visual" por el emplazamiento de antiestéticas "torres" que además han impactado en el valor de los inmuebles linderos y cercanos $[\ldots]$.

La estética y el planeamiento urbano no vuelven a aparecer, posteriormente, en la resolución definitiva.

En el segundo fallo que tratamos en este apartado, caratulado "Castellani, Carlos y E. y otros", de fecha 11.03.03, posterior a la sanción de la ley de Política Ambiental Nacional -, el Tribunal Superior de Córdoba, también descarta la aplicación de la lógica precautoria.

El caso se desarrolla en la ciudad de Oncativo en la provincia de Córdoba. Se inicia por la interposición de una acción de amparo a través de la cual se solicita la suspensión 
de la autorización para instalar antenas de telefonía celular en la localidad de Oncativo. La acción tendía a la suspensión de instalación y eventual erradicación de cuatro antenas de telefonía móvil, debido a que considera que de su instalación deviene la violación de derechos con jerarquía constitucional como son el medio ambiente, la salud y la propiedad. Asimismo, introduce criterios estético - urbanísticos.

En la primera instancia el Juzgado de Instrucción, Menores y Faltas de Río Segundo rechazó la acción. La Cámara de Acusación de Córdoba confirmó el auto apelado.

En la tercera instancia el Tribunal Supremo decidió por dos votos contra uno confirmar nuevamente la resolución, declarando improcedentes los recursos planteados.

Este Tribunal destaca que

[...] en la medida en que no se encuentra acreditada la lesión manifiesta a la salud, a la vida y al medio ambiente que - según los impugnantes - causaría la exposición a campos eléctricos y magnéticos...no se han logrado pruebas fehacientes que permitan concluir que existan consecuencias negativas de la exposición a campos electromagnéticos sobre la salud o el ambiente [...].

Por ende, ante la falta de certeza, se da lugar a la realización de la actividad hasta tanto se compruebe que existe efectivamente peligro de causación de daños en la salud o en el medio ambiente.

El Tribunal sostiene, por otra parte, que toda actividad conlleva un riesgo asociado y efectúa una comparación con el caso del riesgo de conducir un automóvil "[...] el simple hecho de conducir un automóvil conlleva un riesgo, sin embargo no por ello se prohíbe su utilización [...]". En esta frase podemos vislumbrar una confusión en cuanto al carácter del riesgo que se está considerando. En el caso del automóvil estamos en presencia de un riesgo previsible, el cual puede ser estudiado en base a criterios de regularidad y respecto del que se hace factible el funcionamiento del instituto del seguro. Es un caso cuya naturaleza nos introduce en el paradigma de la solidaridad. En el supuesto de los campos electromagnéticos, como hemos ya afirmado, estamos en presencia de una hipótesis imprevisible. Ello en virtud de que no se cuenta con información suficiente como para determinar si existe vinculación causal cierta entre la generación de radiaciones no ionizantes y el daño a la salud humana o al medio ambiente.

Por otro lado, se observa un argumento confuso dado que a renglón seguido de la comparación precedentemente citada, se introduce el concepto de posibilidad que se corresponde con los riesgos imprevisibles. Es así como se afirma que

[...] Del mismo modo no se puede impedir la instalación de las antenas de telecomunicaciones - las cuales prestan servicios importantísimos a la población - por la mera posibilidad de que éstas configuren un peligro a la salud o al medio ambiente, contrarrestable o neutralizable en la medida que se cumpla con las normas de seguridad [...]. 
La actora, por su parte, introduce el concepto de imprevisibilidad respecto del riesgo, y - de la misma manera que en el caso jurisprudencial anterior - refiere a la negativa de algunas empresas de seguro a suscribir pólizas que aseguren "[...] los riesgos de daños a la salud por parte de los usuarios [...]". De esta manera, se vuelve a visualizar la rigidez que se presenta para el funcionamiento del instituto del seguro.

Otro de los elementos que se repite es la importancia del discurso experto al momento de fundar el decisorio. Se considera relevante que

[...] el dictamen de la mayoría de la Comisión sobre la Contaminación Visual, Sonora y Electromagnética de las antenas de comunicación... señala la exposición a la radiación de radiofrecuencia...no causan efectos adversos en la salud de la población en general...Los vacíos de conocimiento en la materia son suficientes para que en este momento no sea posible asegurar que la exposición a radiación $\mathrm{RF}$, aún para niveles inferiores a los más exigentes recomendados internacionalmente, carece completamente de efectos potencialmente adversos para la salud (énfasis agregado) [...].

También, señalamos que se resaltan las conclusiones elaboradas por la OMS

[...] la Organización Mundial de la Salud ha iniciado el "Proyecto Internacional de Investigación de Campos Electromagnéticos" para dar respuesta a la preocupación que causa a la población mundial la radicación de antenas...hasta tanto dicho estudio no concluya no hay pronunciamiento científico ecuménico que otorgue pruebas convincentes de los efectos nocivos de la radiación no ionizante sobre el organismo [...].

Ahora bien, en el presente fallo hay un voto en disidencia del Dr. Juan C. Cafferata que es interesante destacar debido a que afirma la procedencia de aplicación del principio precautorio.

Asimismo, lo consideramos relevante debido a que si bien subyace una lógica de tratamiento del supuesto como daño a la salud, se considera que el principio precautorio es aplicable a ese ámbito, ampliando su margen de actuación.

Concibe como contradictorio que el Tribunal haya señalado la posibilidad de provocación de daños en la salud o el medio ambiente por parte de la generación de ondas electromagnéticas y luego no aplique un criterio precautorio.

[...] La sentencia en recurso, luego de señalar la falta de certeza acerca de la potencial aptitud dañosa de las antenas de telefonía celular, no ha tenido en cuenta que de esa falta de certeza se deriva un riesgo para la salud humana y para el medio ambiente, ante la contingencia o proximidad de la producción de daños...la misma falta de certeza determina la existencia de un riesgo consistente en la eventualidad de que los daños en definitiva se puedan producir [...].

Resalta que la esencia del principio de precaución 
[...] es que la sociedad no puede esperar hasta que se conozcan todas las respuestas, antes de tomar medidas que protejan la salud humana o el medio ambiente de un daño potencial...La precaución es necesaria cuando dos circunstancias se presentan a la vez: a) falta de certidumbre científica y b) amenaza de daño al ambiente o a la salud humana $[\ldots]$.

El juez disidente concluye que se verifican ambos extremos en autos. Se funda, principalmente, en los discursos provenientes de expertos que fueran agregados al expediente, de los cuales deduce una interpretación contraria a la expuesta por la mayoría.

Por su parte, el argumento del juez disidente se basa en criterios preponderantemente asociados a la salud humana y en menor medida ambientales. Sostiene dentro de sus afirmaciones que

[...] Los artículos periodísticos y las opiniones de expertos acompañados nos alertan acerca de la posible existencia de daños de distinta gravedad, que van desde cambios en la actividad normal del cerebro, en el tiempo de reacción y en los patrones de sueño, hasta determinados tipos de cáncer, sobre todo linfomas y leucemias, que lógicamente pueden ser aptos para desencadenar la muerte de los afectados, lesionando con mayor intensidad a la población infantil [...]; [...] El mentado riesgo se refiere a derechos fundamentales del hombre...derecho a la vida...derecho a gozar de un medio ambiente sano... Ante la mera posibilidad de existencia de un riesgo grave e irreversible a tales derechos humanos, no podemos permanecer impasibles $[\ldots]$.

Introduce la racionalidad precautoria como herramienta de prevención,

[...] Las medidas preventivas cuya adopción postulo responden a lo que se conoce como el "principio de precaución [...] Nuestra Constitución Provincial establece este principio en su artículo 59 al establecer que el sistema de salud incluye el control de los riesgos biológicos, sociales y ambientales de personas, desde su concepción [...]; [...] Tales medidas, en el caso, imponen evitar la instalación de las antenas en zonas residenciales, derivándolas a otros lugares en donde se suprima en riesgo...considero que pueden conjugarse y equilibrase el goce de todos ellos a través de la instalación de las antenas en zonas en donde su operación no presente riesgos para la salud y el ambiente $[\ldots]$.

En tanto que el voto de la mayoría refiere a criterios socioeconómicos, “[...] no se puede impedir la instalación de las antenas de telecomunicaciones - las cuales prestan servicios importantísimos a la población [...]”.

Refiere a la inadecuación de ciertos institutos para la gestión del caso, dado que las vías alternativas que se proponen para dar tratamiento a la hipótesis de hecho: acción de obra nueva y acción de daño temido no son idóneas. Han sido pensadas para otro tipo de circunstancias,

[...] el artículo 2499 del Código Civil...se trata de una acción posesoria concedida a quien viere afectados sus derechos posesorios, lo que no sucede en autos en que los derechos en juego son los de la salud y el medio 
ambiente...tampoco es aplicable al "sub lite" el artículo 2500 del Código Civil desde que nada hay en el caso que requiera ser debatido en una acción real o interdicto posesorio [...].

En el caso bajo examen, el magistrado disidente señala que se hace necesario tomar medidas de prevención. En el supuesto concreto las mismas

[...] imponen evitar la instalación de antenas en zonas residenciales, derivándolas a otros lugares en donde se suprima el riesgo. Contrapesados los derechos constitucionales en juego (el derecho del municipio a usufructuar su propiedad, el derecho a trabajar y ejercer toda industria lícita del prestador del servicio, el derecho a la salud y a un medio ambiente sano de los actores), considero que pueden conjugarse y equilibrarse el goce de todos ellos a través de la instalación de las antenas en zonas en donde su operación no presente riesgos para la salud y el ambiente [...].

\section{Sobre dificultades de aprehensión}

El análisis del caso expuesto deja traslucir la dificultad que el derecho, como herramienta de gestión de riesgos ambientales, presenta al momento de dar tratamiento a hipótesis cuyas consecuencias dañosas son inciertas.

La conjunción de discursos y prácticas, que confluyen a la hora de tratar este tipo de hipótesis híbridas, presentan un panorama desordenado, “incoherente” y, por ende, de difícil aprehensión para el ordenamiento jurídico.

Ahora bien, la lógica precautoria puede constituirse como un instrumento que coadyuve a la gestión de este tipo de casos complejos, dado que en su seno constitutivo se halla la idea misma de incertidumbre.

Cabe señalar, sin embargo, que la introducción de esta racionalidad como variable dentro esquema del derecho de daños, específicamente del daño al medio ambiente y a la salud humana, da lugar a una serie de dificultades que devienen en un conflicto epistemológico, visible a partir de las contradicciones que se generan a la hora de su aplicación. Ello puede visualizarse en los discursos analizados precedentemente, donde se entremezclan elementos correspondientes a las lógicas de responsabilidad, solidaridad y seguridad.

Como hemos ya señalado, podría pensarse en la modificación de ciertos presupuestos de la responsabilidad, posibilitando afirmar que el daño no necesariamente debe ser cierto, ni la relación de causalidad, en todos los casos, adecuada.

Por otro lado, se podría intentar la conformación de una herramienta de gestión del riesgo, que pueda encuadrarse dentro del ordenamiento jurídico, como normativa cuyo eje sea este tipo de problemáticas. Que, por consecuencia, inscriba en su seno la racionalidad precautoria, y, por consiguiente, la noción de incertidumbre. 
Ahora bien, sería importante conjugar la noción de incerteza con la necesaria búsqueda de rigurosidad científica, a los fines de tratar de reducir su margen. Ello mediante la asignación de relevancia a la problemática posiblemente perjudicial, y a través de la organización de medios necesarios para la promoción y agilización de estudios pertinentes.

Por último, es dable señalar que dentro de este marco, la lógica precautoria, confiere otra posibilidad que es la de dar lugar a cierta apertura hacia otras esferas del conocimiento. Es decir, ampliar los discursos en base a los cuales sustentar las decisiones, mediante la incorporación de afirmaciones que han sido olvidadas bajo la preeminencia del discurso experto, entendido éste, a partir de la modernidad, como única forma de conocimiento. ${ }^{37}$

\section{Abstract}

The present work is based in a case study in which argentinian jurisprudence about electromagnetic field is revised. We analyse the difficulties that the precautionary rationality generates in the operation of the Responsibility Law when a controversial scientific context is involved.

Keywords: Precautionary principle. Environmental risk. Radiation. Antenas for telephony

\section{Referências}

A SACAR las ondas del colegio. La Nación, Buenos Aires, 26 oct. 2006. p. 12.

ANTENAS de celulares: controlan por primera vez sus radiaciones. Clarín, [Buenos Aires], 9 mayo 2006.

ANTENAS de telefonía móvil invaden la ciudad. La Nación, Buenos Aires, 5 nov. 2006.

BECHMANN, Gotthard. Riesgo y sociedad post moderna en Gobernar los riesgos, ciencia y valores en la sociedad del riesgo. Madrid: OEA, 2004. (Biblioteca Nueva).

BECK, Ulrich. La sociedad del riesgo global. Madrid: Siglo XXI de España, 2002.

BECK, Ulrich. La sociedad del riesgo: hacia u na nueva modernidad. [Barcelona]: Paidos, 1998.

BRAILOVSKY, Elio Antonio; FOGUELMAN, Dina. Memoria verde: historia ecológica de la Argentina. Buenos Aires: Sudamericana, 1991.

CAFFERATTA, Néstor. Daño ambiental y colectivo. Ponencia elaborada con motvio de las "II

${ }^{37}$ SANTOS, Boaventura de Souza. A globalicacio e as ciencias sociales. [S.1.]: Cortes, 2000. 
Jornadas Provinciales y I Latinoamericanas sobre Medio Ambiente”. Salta, Argentina. 13,14 y 15 de mayo de 2004.

CAFFERATTA, Néstor. Responsabilidad por daño ambiental. In: REPRESAS, Félix A. Trigo; MESA, Marcelo J. López. Tratado de derecho de la responsabilidad civil. Buenos Aires: La Ley, 2004.

CAMPIONE, Roger. El que algo quiere algo le cuesta: notas sobre la Kollateralschädengesellschaft. In: LA SEGURIDAD en la sociedad del riesgo: un debate abierto. Barcelona: Atelier, 2003.

CARR, S.; IBARRA, A. Las construcciones del riesgo en Gobernar los riesgos. In: CIENCIA y valores en la sociedad del riesgo. Madrid: OEA, 2004. (Biblioteca Nueva).

COMISIÓN INTERNACIONAL PARALA SEGURIDAD ELECTROMAGNÉ-TICA(ICEMS). Resolución de Benevento. Montepulciano, 19 sep. 2006. Página web: <www.icems.eu>. Fecha de acceso: 10 dic. 2006

DOUGLAS, Mary. La aceptabilidad del riesgo según las ciencias sociales. Buenos Aires: Paidos, 1996.

EWALD, François. Le principe de précaution. Que sais je? Paris: PUF, 2001.

EWALD, François. Le retour du malin génie. Esquisse d'une philosophie de la précaution. In: GODARD, Olivier (Dir.). Le principe de précaution dans la conduite des affaires humains" Paris:Editorial de la Maison des Sciences de l'homme, 1997.

EWALD, François. Philosophie de la précaution. L'Année sociologique, Paris, n. 46-2, 1996.

GIDDENS, Anthony et al. Las consecuencias perversas de la modernidad. Barcelona: Anthropos, 1996.

HERMITTE, Marie-Angèle. La fondation juridique d'une société des sciences et des Techniques par les crises et les risques. Paris: [S.n.], 2006/7. Material del Seminario "Droit des sciences et techniques" dictado en la EHESS.

INDEMNIZARÁN a una familia por los daños provocados por una antena. La Nación, Buenos Aires, 24 abr. 2007. p. 12.

JONAS, Hans. Le principe responsabilité. Paris: Ed. du Cerf, 1990.

KOURILSKY, Philippe; VINEY, Genevieve. Le principe de précaution. Rapport au Premier Ministre. Paris: Ed. Odile Jacob, 1999. (La documentation Française).

LA JUSTICIA avala la instalación de antenas. La Voz Del Interior, [S.1.], 12 mar. 2003.

LATOUR, Bruno. Nous n'avons jamais été modernes: essai d'anthropologie symétrique: la decouverte. Paris: [s.n.], 1997. 
NOIVILLE, Christine. Science, décision, action: trois remarques à propos du principe de précaution. Petites affiches, Paris, n. 218-219, 1 ${ }^{\mathrm{er}}-2$ nov. 2004.

ORGANIZACIÓN MUNDIAL DE LA SALUD. ¿Qué son los campos electromagnéticos? Disponible em: <www.who.int/peh-emf/es>. Fecha de acceso: 10 dic. 2006.

ORGANIZACIÓN MUNDIAL DE LA SALUD. Estableciendo un diálogo sobre los riesgos de los campos electromagnéticos. OMS. Ginebra, 2005.

PRIEUR, Michel. Incertitude juridique, incertitude scientifique et protection de l' environnement" en "Incertitude juridique, incertitude scientifique". Les Cahiers du Crideau, [S.1.], n. 3, 2001.

RECLAMO por una antena en un colegio. Clarín, [Buenos Aires], 29 mayo 2006.

SANTOS, Boaventura de Souza. A globalicacio e as ciencias sociales. [S.1.]: Cortes, 2000.

SE HABILITARON las primeras antenas de telefonía celular. El Litoral, 23 oct. 2005.

SOZZO, Gonzalo. Riesgos del desarrollo y sistema del derecho de daños (hacia un derecho de daños pluralista). In: DIREITO, sociedade e riscos. A sociedade contemporânea vista a partir da idéia de risco. Red Latino - Americana e Européia sobre Governo dos Riscos. Brasilia: [s.n.], 2006.

THIBIERGE, Catherine. Libres propos sur le droit de la responsabilité. Vers un élargissement de la fonction de la responsabilité civile? Revue Trimestral de Droit Civile, Paris, Jui./Sep. 1999.

UNA MEDIDA judicial de altísimo voltaje”, "El debate llegó a la OMC”, "Lo que dice Edesur”. p. 12,16 de julio de 2003 . 